\title{
ПАТОГЕНЕТИЧЕСКИЕ АСПЕКТЫ ИМУННОГО ОТВЕТА ПРИ ЛОКАЛЬНО-ИНФЕКЦИОННО-ВОСПАЛИТЕЛЬНЫХ ЗАБОЛЕВАНИЯХ И СЕПСИСЕ У ДЕТЕЙ РАННЕГО ВОЗРАСТА
}

\section{PATOGENETIC ASPECTS OF IMMUNE RESPONSE TO LOCAL INFECTIOUS-INFLAMMATORY DISEASES AND SEPSIS IN INFANTS}

S. Maharramova

Summary. Socio-biological factors have a negative impact on the nature of local infectious-inflammatory diseases and sepsis in infants (type of nutrition, pregnancy complications, CNS hypoxia, thymomegaly, dysbacteriosis, hypotrophy, rickets, anemia, acute respiratory viral infection). In infants born as a result of physiological pregnancy and fed naturally, local infectious-inflammatory diseases were mild in $93.7 \%$ of cases. $55.4 \%$ of infants born as a result of pathological births and fed artificially had a severe form of local infectious-inflammatory diseases. In infants with premorbid background and concomitant thymomegaly and dysbacteriosis, severe forms of local infectious-inflammatory diseases were found in $84.0 \%$ and $82.2 \%$ of cases, respectively.

Keywords: LiiD, sepsis, immune systems, immunoglobins, infants.

\author{
Магеррамова Сара Гусейнага гызы \\ H.с., Институт Генетических ресурсов НАН \\ Азербайджана, г. Баку \\ huseynaga.gurbanov@gmail.com
}

Аннотация. Социально-биологические факторы негативно влияют на характер местных инфекционно-воспалительных заболеваний и сепсиса у новорожденных (тип питания, осложнения беременности, гипоксия ЦНС, тимомегалия, дисбактериоз, гипотрофия, рахит, анемия, ОРВИ). У новорожденных, рожденных в результате физиологической беременности и вскармливаемых естественным путем, местные инфекционно-воспалительные заболевания протекали в легкой форме в 93,7\% случаев. $55,4 \%$ новорожденных, рожденных в результате патологических родов и вскармливаемых искусственно, имели тяжелую форму местных инфекционно-воспалительных заболеваний. У детей грудного возраста с преморбидным фоном и сопутствующей тимомегалией и дисбактериозом тяжелые формы местных инфекционно-воспалительных заболеваний выявлялись в 84,0\% и 82,2\% случаев соответственно.

Ключевые слова: LïD, сепсис, иммунный систем, иммуноглобины, дети грудного возраста.

в современной литературе по иммунологии нет конкретных данных, касающихся влияния того или иного преморбидного фона на иммунную систему ребенка при лИВЗ.

В последние 20 лет, при рассмотрении перехода локальных воспалительных процессов в сепсис, особое внимание уделяется роли дисбактериоза в кишечнике. Как при одной, так и при другой болезни может наблюдаться дисфункция иммунной системы и снижение защитных сил организма, что в свою очередь может способствовать переходу локального воспалительного процесса в сепсис [5].В литературе имеются очень скудные сведения, относительно лечебных и профилактических мер, которые при терапии локальных воспалительных заболеваний и сепсиса грудных детей проводятся в зависимости от преморбидного фона либо тех или иных иммуно- метаболических изменений. Помимо того, что сведений очень мало, они носят еще и противоречивый характер, что лишний раз подтверждает необходимость и важность проведения соответствующих исследований в данной области. Стало очевидным, что в основе патогенеза сепсиса лежит запуск цитокиново- 
го каскада, включающего продукцию как провоспалительных, так и противовоспалительных цитокинов. Баланс между этими оппозитными группами медиаторов во многом определяет характер течения и исход гнойно- септических заболеваний $[8,12,15]$.Однако, несмотря на это в современной литературе по иммунологии нет конкретных данных, касающихся влияния того или иного преморбидного фона на иммунную систему ребенка при локальных инфекционно-воспалительных заболеваниях. Также отсутствуют сведения о переходе (трансформации) локальных воспалительных заболеваний в сепсис в результате воздействия вредных социально-биологических факторов. Учитывая изложенное выше, мы поставили себе целью осуществить настоящую исследовательскую работу.

\section{Цель исследования}

Цель исследования заключалась в изучении роли некоторых социально-биологических факторов, вида питания младенца, особенностей внутриутробного развития, тимомегалии, дисбактериоза, ОРВИ (острой респираторной вирусной инфекции) в трансформации ЛИВ3 в сепсис у детей грудного возраста и обосновании аргументированных подходов лечения.

\section{Метолы исслеАования}

Под нашим наблюдением находилось 487 грудных младенцев с ЛИВ3. Для сравнения иммуно-метаболических параметров были отобраны 60 практически здоровых детей. Эти дети соответственно возрасту были разделены на 3 группы: I группа - 20 детей в возрасте 1-6 месяцев; II группа - 20 детей в возрасте 7-12 месяцев; III группа - 20 детей в возрасте 1-3 лет. Для выяснения состояния клеточного иммунитета, путём использования моноклональных антител, определяли Т-лимфоциты и их субпопуляции CD3+, CD4+, CD8+, CD14+, CD16+, CD19+. В настоящее время это считается самым надежным исследованием. Для определения функциональной активности лимфоцитов использовалась реакция бласттрансформации[7]. С целью изучения состояния гуморальной иммунной системы с помощью метода определяли в сыворотке крови количество иммуноглобулинов A, M, G (IgG1, G2, G3, G4). Количество İE в сыворотке крови устанавливали иммуноферментным методом, с использованием реактивов швейцарской фирмы "Pharmacia Diagnostic AB". Наряду с иммуноглобулинами в сыворотке крови определяли также мало-, средне- и крупномолекулярные белковые фракции циркулирующих иммунокомплексов (ЦИК). Для выявления показателей неспецифического иммунитета определяли количество нейтрофилов в 1 мкл крови. Функциональную активность нейтрофилов устанавливали посредством теста восстановления ни- тросинего тетразолия (НСТ-тест). На начальном этапе исследования для выявления пренатальных факторов риска и роли преморбидных состояний в трансформации ЛИВ3 и сепсис в постнатальном периоде, исследуемые дети были разделены на группы следующим образом. В I группу были включены 16 детей, родившихся в ходе физиологической беременности и физиологических родов. Во II группу вошли 18 детей, родившихся в результате патологической беременности, но при физиологических родах. В III группу были включены 15 детей, родившихся от матерей с нефропатией беременности при патологических родах. У этих детей в раннем неонатальном периоде выявлялось гипоксическое повреждение центральной нервной системы I и II степени. B IV группу вошли 18 детей, матери которых во время беременности страдали нефропатией. У этих детей к ЛИВ3 присоединилась еще и ОРВИ. В V группу были включены 18 детей, которые родились после патологически протекавшей беременности. У них ЛИВЗ протекал на фоне тимомегалии I-III степени. B VI группу вошли 28 младенцев грудного возраста, которые были рождены при патологических родах. ЛИВЗ у этих детей развивался на фоне дисбактериоза.

Наряду с этим, для изучения влияния на течение ЛИВ3 преморбидных заболеваний и питания, часть выбранных для исследования больных детей, была сгруппирована также по другому принципу. Эти пациенты были разделены на 3 группы. I группа в этом случае состояла из детей, родившихся после физиологического течения родов. У них постнатальное развитие протекало нормально и они, в свою очередь, были разделены на 2 подгруппы: в подгруппу IA вошли 15 детей с естественным кормлением, а в подгруппу IB15 детей с искусственным кормлением. В группу ІІА вошли 17 детей с ЛИВ3, который развился на фоне рахита и анемии. И наконец, в группу IIIA включили 19 детей с ЛИВ3, который развился на фоне гипотрофии, анемии и рахита.

\section{Результаты исслеАования}

Наши исследования, которые заключались в наблюдении за динамикой протекания локальных инфекционно-вирусных заболеваний подтверждают, что в причине возникновения этой болезни важное значение имеет влияние на организм ребенка анте-, интра- и постнатальных факторов риска. У детей ЛИВЗ чаще всего встречается в результате влияния 2-х и более факторов преморбидного фона(рис.1).У детей, родившихся от физиологической беременности (І группа), в 93,7\% лИВ3 имело легкое течение, а в 6,3\% среднюю степень тяжести. Формы с тяжелым течением не встречались.

У детей, которые родились в результате родов с патологическим течением и были включены во II 


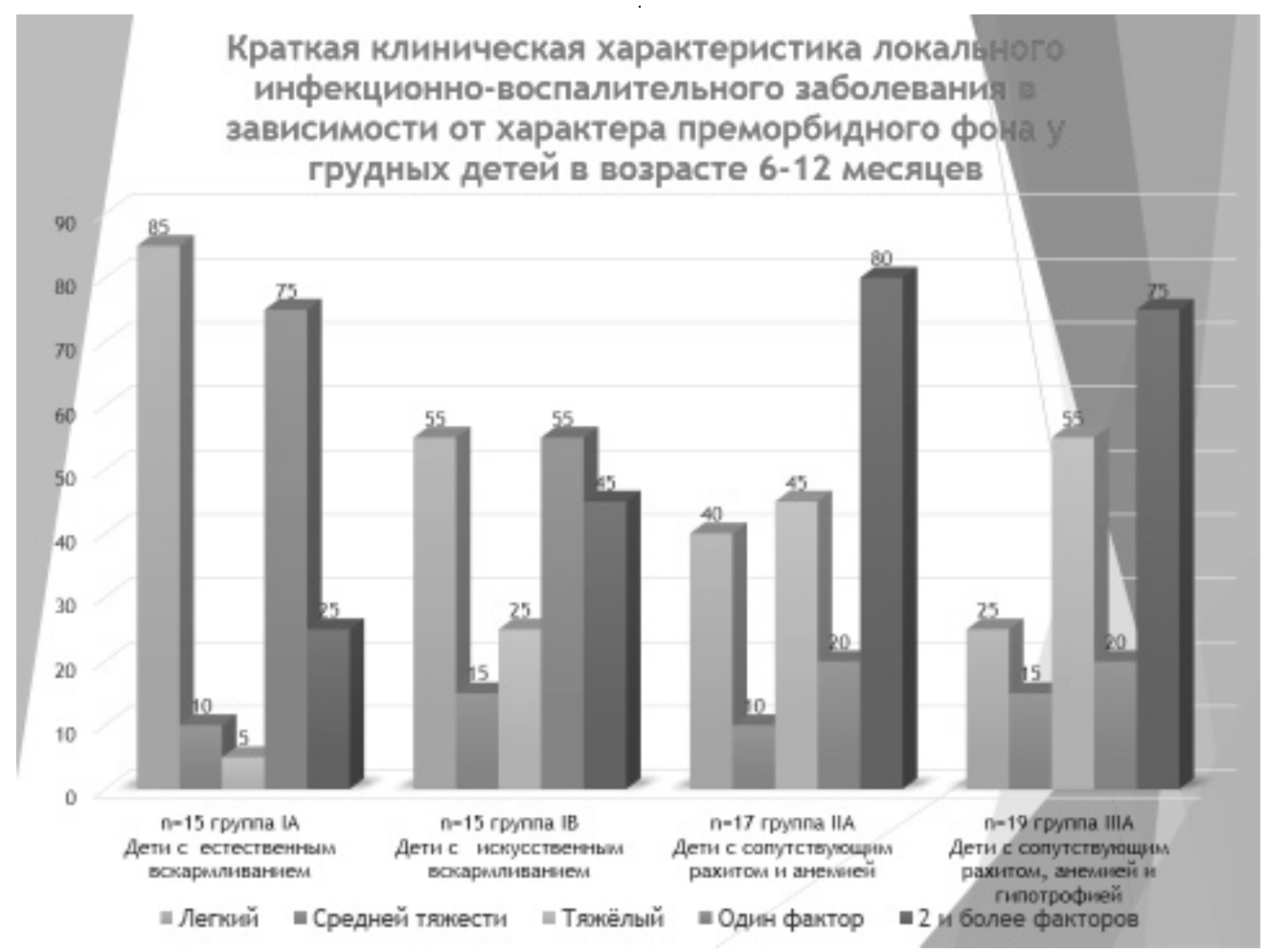

Рис. 1. Краткая клиническая характеристика локального инфекционно-воспалительного заболевания в зависимости от характера преморбидного фона у грудных детей в возрасте 6-12 месяцев

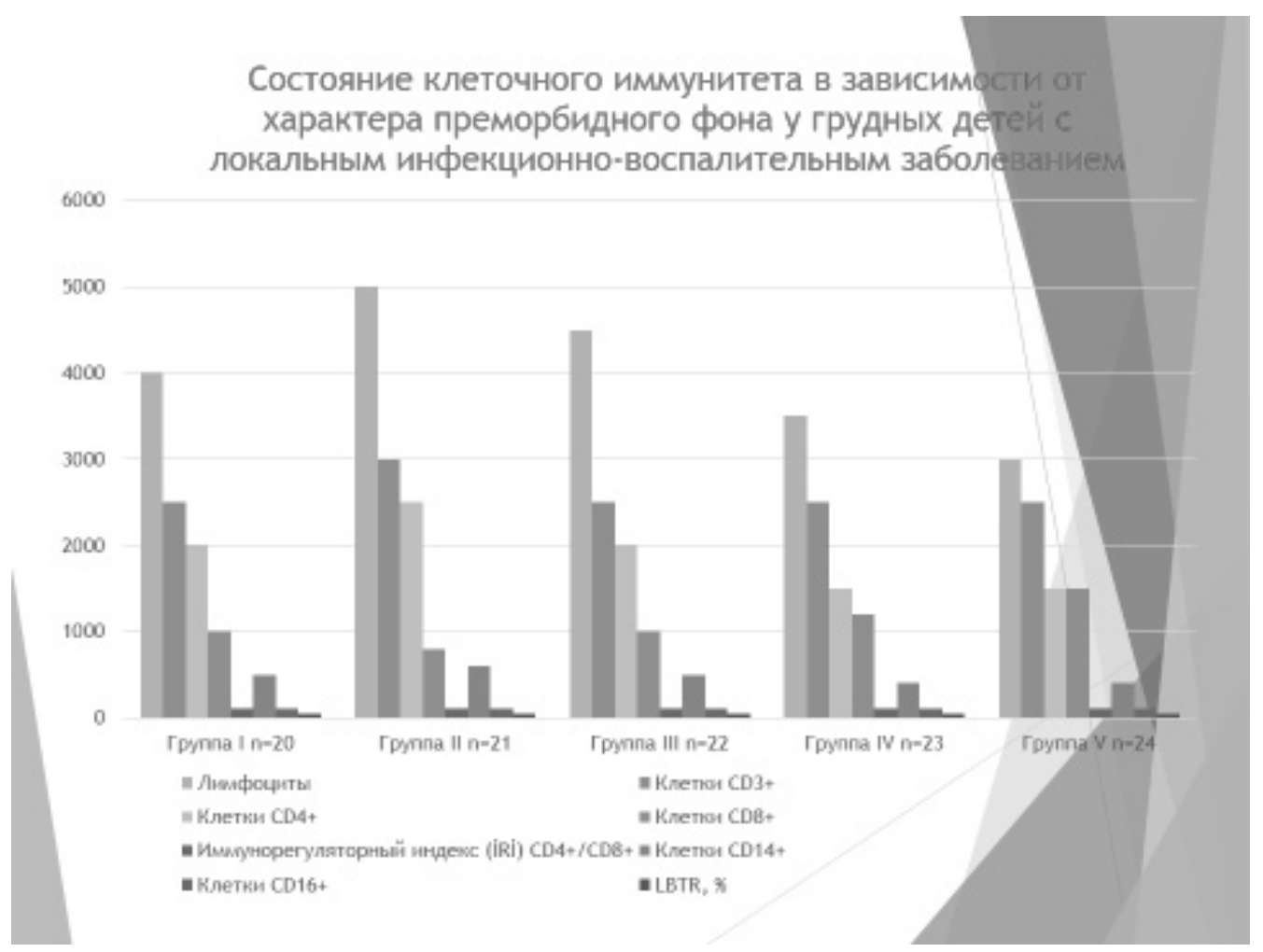

Рис. 2. Состояние клеточного иммунитета в зависимости от характера преморбидного фона у грудных детей. 


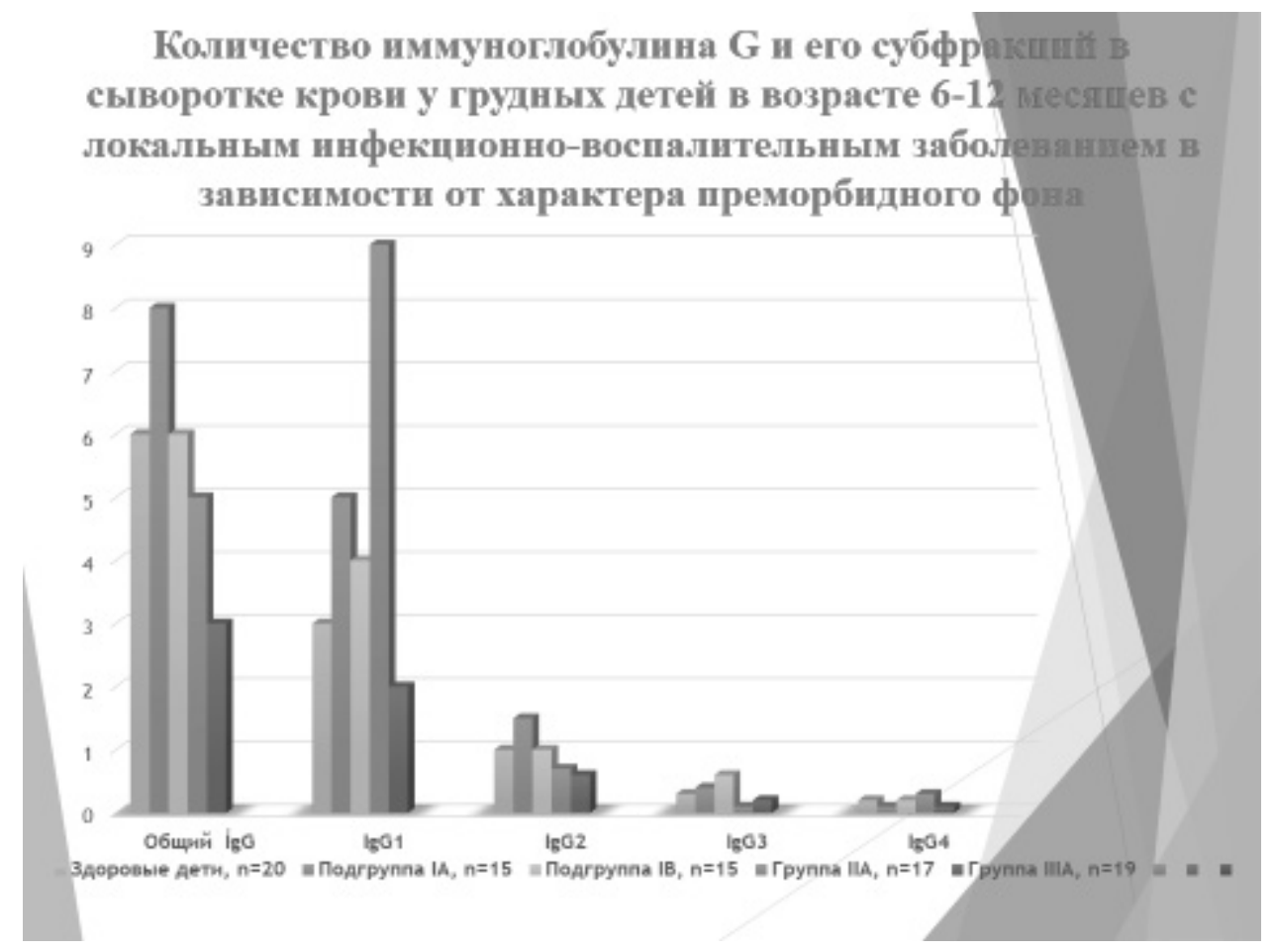

Рис. 3. Состояние клеточного иммунитета в зависимости от характера преморбидного фона у грудных детей с локальным инфекционно-воспалительным заболеванием

группу, ЛИВЗ легкой и средней степени тяжести составили 55,4\% и 27,8\% соответственно. Среди детей, включенных в V группу (у которых была выявлена тимомегалия), доля больных с лёгким течением ЛИВЗ составила всего 4\% от общего числа, а 84\% были с тяжелым течением ЛИВ3. У детей грудного возраста, страдающих ЛИВ3, в зависимости от преморбидного фона в показателях клеточного и гуморального иммунитета были выявлены острые изменения. Наши исследования свидетельствуют, что у 31,3\% детей с ЛИВ3, родившихся в результате нормальной физиологической беременности, выявляется умеренная активация в клеточном и гуморальном иммунитете. Однако, у детей, включенных во 2-ю группу (родившихся от беременности с патологическим течением) в 22,2\% случаев обнаружилось ослабление показателей клеточной иммунной системы. Изменения, аналогичные указанным, мы наблюдали также и в других группах. Например, у детей грудного возраста, у которых ЛИВЗ наблюдался на фоне тимомегалии и дисбактериоза, особенно остро проявлялось состояние иммунодефицита.

На следующем этапе исследований у детей грудного возраста, страдающих ЛИВЗ, изучали состояние иммунной системы в зависимости от вида кормления. У детей с естественным грудным вскармливанием (группа 1А) микроб-антигенные воздействия в 80-87\% случаев становятся причиной активизации клеточно-гуморального иммунитета и неспецифических факторов защиты организма. В то же время у детей с лИВ3, которые находились на искусственном вскармливании (группа 1В), показатели клеточно-гуморального иммунитета были понижены на 20-46\%, а иммунные реакции нейтрофильного генеза соответственно ослабевали на 26,7$46,7 \%$.

У детей грудного возраста, включенных в группу 2А, ЛИВЗ развивался на фоне анемии и рахита. У них отмечалось резкое ослабление функций иммунной системы, существенно сократилось количество Т-лимфоцитов (CD4+ и CD14+ клетки), а также наблюдались ослабление иммунитета нейтрофильного генеза и умеренная нейтропения.

Дети грудного возраста, включенные нами в III группу, в качестве преморбидного фона имели анемию, гипотрофию и рахит. Функции иммунной системы у них были резко ослабленными. У детей из этой группы в результате уменьшения количества CD-4+ клеток (то есть T- хелперов) нарушается синтез иммуноглобулинов клетками CD-19+ (В-лимфоцитами). По этой причине в сыворотке крови пациентов из указанной группы İg, İgM и İg понижаются и обнаруживаются ниже нормы(рис.3). Нейтропения встречалась у них в 63\% случаев, изменения İgG в 42\% случаев. 
В данном случае, для изучения взаимосвязи между состоянием иммунного гомеостаза и степенью тяжести процесса сепсиса у больного ребенка, определяли состояние клеточного и гуморального иммунитета в крови у15 детей со средней формой сепсиса и 20 детей с тяжелой формой сепсиса. Анализ указанных иммунологических параметров и некоторых показателей неспецифического иммунитета показал, что вне зависимости от степени тяжести септического процесса у этих детей во всех показателях иммунной системы, по сравнению со здоровыми детьми, наблюдаются достоверные изменения. Эти изменения выражаются в увеличении количества CD+8 T-супрессоров и понижении других иммунологических показателей - лимфоцитов, CD3+ (Т-лимфоцитов), CD4+ (Т-хелперов), CD14 и CD16 клеток(рис.2), а также индекса иммунорегуляции и БТРЛ (бластотрансформационной реакции лимфоцитов).

При индивидуальном анализе иммунологических параметров каждого пациента выявили, что параметры клеточного иммунитета при средней тяжести течения сепсиса были ниже минимального показателя нормы в 34-67\% случаев, при тяжелом его течении - в 45$85 \%$ случаев. У детей грудного возраста с ЛИВ3, изучали показатели гуморального иммунитета в зависимости от отягчающего преморбидного фона. В данном случае выявили изменения в количестве иммуноглобулинов. Так, например, количество İg по сравнению с нормой уменьшилось в 1,5 раза. Видимо причиной этого является воздействие бактериальных факторов на процесс дифференциации клеток CD4+ (хелпер) и CD+8 (супрессор).

Краткая клиническая характеристика локального инфекционно-воспалительного заболевания в зависимости от характера преморбидного фона у грудных детей в возрасте 6-12 месяцев

В формировании иммунологических реакций в организме активно участвуют субфракции İgG - İgG1, İgG2, İgG3, İgG4(рис. 3). Субфракции İgG1 и İgG3 ускоряют опсонизацию бактерий, повышают фагоцитарную активность макрофагов и нейтрофилов. А субфракции
İgG2 и İgG4 состоят из полисахаридных антител бактерий. Как видим на слайде, у грудных детей с ЛИВЗ в возрасте 6-12 месяцев, уровни субфракций İg3 и İg4 понизились.

\section{Выво $\Delta$}

1. У детей грудного возраста на характер протекания локального ЛИВЗ и сепсиса негативно влияют соцаильно-биологические факторы (вид кормления, осложнения беременности, гипоксическое повреждение ЦНС, тимомегалия, дисбактериоз, гипотрофия, рахит, анемия, подключение острой респираторной вирусной инфекции).Степень тяжести ЛИВЗ зависит от наличия или отсутствия указанных выше преморбидных состояний. У детей, родившихся от беременности с физиологическим течением и естественным кормлением, лИВ3 в 93,7\% случаев оказывается с легким течением. У детей, которые родились в результате родов с патологическим течением и были на искусственном вскармливании, в 55,4\% ЛИВ3 протекала тяжело. Дети, имевшие преморбидный фон и сопутствующую тимомегалию либо дисбактериоз, в 84,0\% и 82,2\% случаев, соответственно, обнаруживали тяжёлое течение ЛИВ3.

2. Изменение у детей грудного возраста таких параметров иммунной системы, как количество продуктов перекисного окисления липидов и молекул с малой массой (ММM), играют важную роль в механизме патогенеза развития ЛИВЗ и сепсиса. Имеется определенная взаимосвязь между изменением указанных показателей и особенностями клинического течения заболевания. В этой взаимосвязи большое значение имеет характер преморбидного фона.

3. У детей грудного возраста для уточнения диагностики сепсиса, прогнозирования трансформации ЛИВЗ в сепсис и для определения вероятных результатов заболевания (выздоровление, осложнение и летальный исход) иммунные параметры (CD4+, CD16+, LBRT, İgG2, İgG4) могут считаться достоверными критериями в установлении динамики патологического процесса.

\section{ЛИТЕРАТУРА}

1. Ганковская 0.А. «Исследование ассоциации полиморфных маркеров генов TLR2 и TLR9 с преждевременными родами и внутриутробным инфициро ванием» //Медицинская иммунология, 2010, № 1-2, с. 87-94.

2. Ганковская Л.В., Намазова-Баранова Л.С., Порядин Г.В., и др. Изменение показателей врожденного иммунитета при тяжелой бронхиальной астме у детей //Медицинская иммунология, 2019. Т. 21, № 1, с. 99-106.

3. Глинцбург А.Л., и др. «Экзогенные и эндогенные факторы в патогенезе атеросклероза. Рецепторная теория атеросклероза». //Российский кардиологический журнал 2010, № 2, с. 92-96.

4. Глущенко В.А. Структура заболеваемости внутрибольничными инфекциями в многопрофильном стационаре//Глав врач, 2017, № 5-6, с. 40-43. 
5. Макаров О.В., Ковальчук Л.В., Ганковская Л.В и др. Невынашивание беременности, инфекция, врожденный иммунитет. М.: ГЭОТАР-Медиа, 2007, 196 с.

6. Малкова Е.М., Помогаева А.П., Кравец Е.Б. и. др. Внутриутробные инфекции у новорожденных: использование генодиагностики, клинические особенности и подходы к лечению // Педиатрия.-2003.-№ 1.-С.36-40.

7. Манина И.В., Сергеев В.Ю., Голубцова Н.В., Сергеев А.Ю. Модификация реакции бласттрансформацию лимфоцитов для применения в аллергологической практике//Российский биотерапевтический журнал. 2018, Т. 17, № 2, с. 88-92.

8. Ризванова Ф.Ф., Пикуза 0.И., Файзуллина Р.А. Генетическая диагностика: полиморфизм генов цитокинов // Прак. медицина, 2010, т. 45 , № 6, с. 41-43.

9. Свистушкин В.М. Бактериальнык инфекции лор-органов: деликатная терапия // Медицинский совет. 2017, № 8, с. 58-63.

10. Annunziato F., Romagnani S. The transient nature of the Th17 phenotype //Eur. J. Immunol., 2010, vol. 40 № 12, p.3312-3316.

11. Brown, G.D.; Willment, J.A.; Whitehead, L. C-type lectins in immunity and homeostasis. Nat. Rev. Immunol.2018, 18, 374-389.

12. Cayrol, C.; Girard, J.-P. Interleukin-33 (IL-33): A nuclear cytokine from the IL-1 family//Immunol. Rev. 2018,281, pp.154-168.

13. Melern E., Pershagen Pathophysiology of asthma: lessons from genetic research with particular focus on severe asthma// J. of Internal Medic. 2012, vol. 272, № 2, p. 108-120.

14. Redegeld, F.A.; Yu, Y.; Kumari, S.; Charles, N.; Blank, U. Non-IgE mediated mast cell activation//Immunol. Rev.2018, 282, 87-11

15. Wojcik-Pszczola K., et al. Connective tissue growth factor regulates transition of primary bronchial fibroblasts to myofibroblasts in asthmatic subjects//Cytokine, 2018, Vol. 102, pp. 187-190.

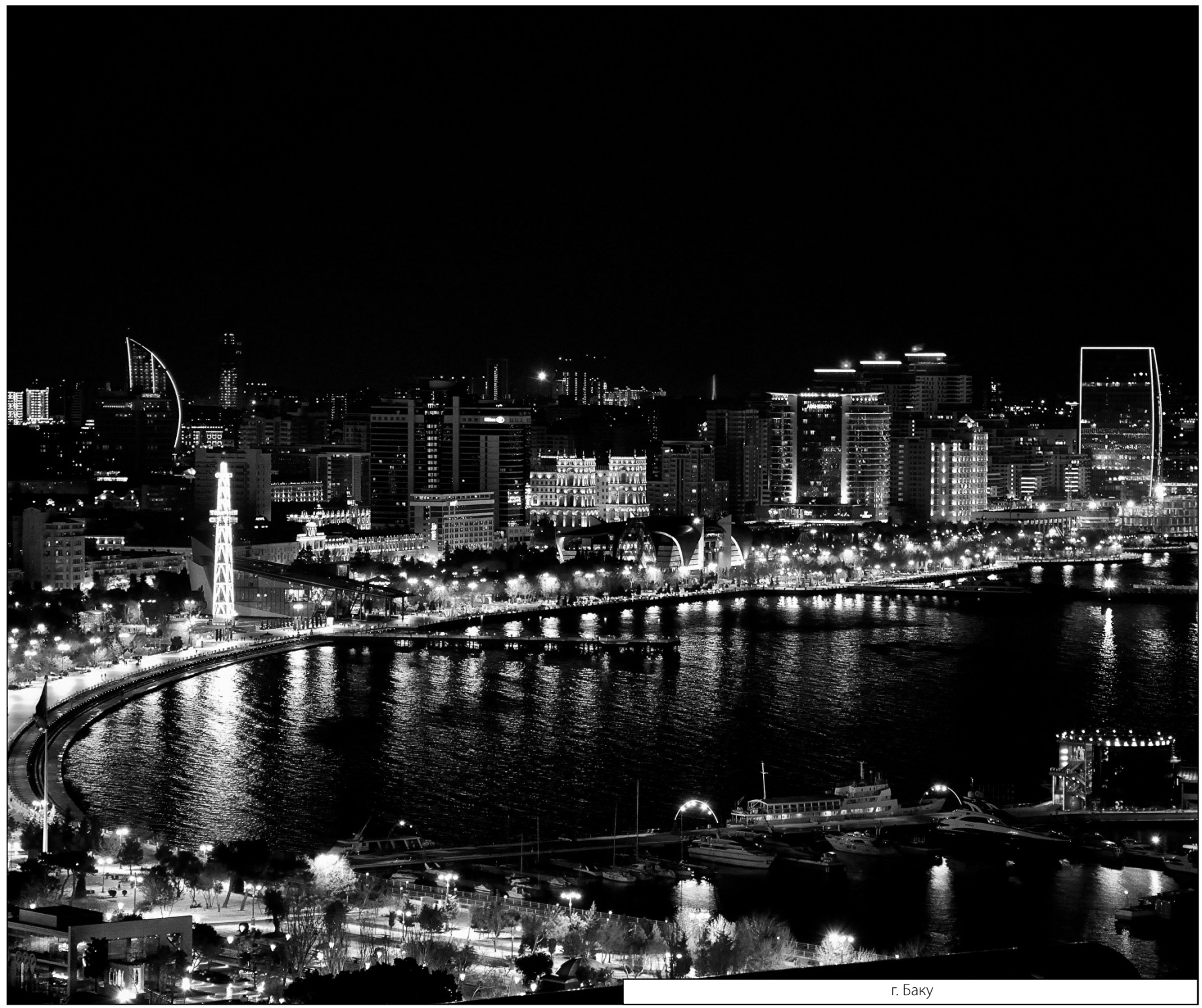

